\title{
Developing student connectedness under remote learning using digital resources: A systematic review
}

\author{
Elizabeth Hehir $^{1} \mathbb{D} \cdot$ Marc Zeller $^{1} \mathbb{D} \cdot$ Joanna Luckhurst $^{1} \mathbb{D} \cdot$ Tara $^{\text {Chandler }}{ }^{1} \mathbb{D}$
}

Received: 17 February 2021 / Accepted: 3 May 2021 / Published online: 28 June 2021

(C) The Author(s), under exclusive licence to Springer Science+Business Media, LLC, part of Springer Nature 2021

\begin{abstract}
Online learning is negatively associated with student connectedness. Due to the COVID-19 pandemic, Higher Education (HE) institutions have pivoted to blended and online learning. Subsequently, HE institutions have seen a shift in student connectedness resulting in loneliness, isolation, social and psychological distance. Consequently, it is essential for teacher practitioners to respond with innovative digital learning resources that aim to develop student connectedness. The current systematic review aimed to explore the research question: what are the characteristics of effective digital teaching resources when the aim of the resource is to build student connectedness? This systematic literature review was conducted in line with published guidance for undertaking reviews (Centre for Reviews and Dissemination, 2009). Successively, 17 papers met the inclusion criteria and were analysed using a thematic synthesis approach. Results identified five key themes that are important when designing digital resources to build connectedness: usability; teacher interaction; immediacy; synchronicity; and community. The findings of this research are expected to provide a template to assist teacher practitioners in creating innovative digital resources that facilitate connectedness.
\end{abstract}

Keywords Covid-19 Pandemic · Connectedness · Online learning · Distance learning $\cdot$ Remote learning

\section{Introduction}

Connectedness is defined as the perception of belonging (Lee \& Robbins, 1995). Connectedness is achieved when an individual experiences a sense of social relationship and integration (Kuwabara et al., 2002). Feeling connected increases the likelihood of student health and wellbeing (Arslan, 2021), academic success

Tara Chandler

T.Chandler@Bolton.ac.uk

1 University of Bolton, Deane Road, Bolton BL3 5AB, UK 
(Wilson, 2018), and graduate prospects (Bridgstock et al., 2019). Hence, it can be inferred that feeling connected is an essential component of the student experience. Yet due to the global changes in teaching and learning as a response to the Covid19 pandemic, student interaction in the learning process has been challenged. As a response to the Covid-19 pandemic, education institutions globally have seen a rise in remote, distance, and blended learning approaches (Aristovnik et al., 2020; Motala \& Menon, 2020; Osman, 2020; Thistlethwaite et al., 2020). These digital teaching and learning approaches have become a substitute to in-person classroom settings. Subsequently, students have described feelings of psychological distance, loneliness, isolation, and disconnection from their peers and education institutions (Arslan, 2021). As a byproduct of disconnection, students have reported increased mental health problems (Aucejo et al., 2020; Elmer et al., 2020; Sahu, 2020), heightened anxiety around academic performance, and reduced academic self-efficacy (Alemany-Arrebola et al., 2020).

Arslan (2021) has identified that belongingness or connectedness can moderate the effects of isolation and loneliness. Therefore, connectedness is shown to encourage student psychological health and wellbeing. Connectedness acts as a protective factor against physical and psychological distance and from feelings of isolation and loneliness. However, due to Covid-19 social distancing guidelines, it is essential to encourage connectedness via alternative methods to traditional face-to-face interactions. The successful use of digital resources to maintain social presence and connection is paramount to ensure students feel a sense of control over their socialisation, learning, and assessment. It is therefore essential to ensure that information and communication technologies (ICT) promote social identity and social connection amongst student cohorts. Furthermore, ICT may offer the opportunity for increased avenues of connection through varied mediums i.e., use of smart phones, social networking sites, and topic-specific forums. For example, the use of smart phones for educational purposes has significantly predicted increased feelings of connectedness outside of the classroom involvement (Liu et al., 2016). In addition, increasing the diversity to which students can interact may heighten the likelihood of individuals experiencing connection (Wyn et al., 2005).

While online education has seen a rise in the use of technology platforms, literature now includes the topic of "Zoom Fatigue", referring to experiences of tiredness and anxiety regarding the use of virtual platforms (Wiederhold, 2020). Furthermore, virtual learning is also impacted by technology efficacy amongst students (Lai \& Bower, 2020). Subsequently, Farid et al., (2018) explained that a poorly designed e-learning software is a catalyst for issues around effective learning and a poor design can impact student engagement (Czerkawski \& Lyman, 2016). Poor design can be related to usability, functionality, security, reliability (Farid et al., 2018) and an effective pedagogical framework (Brereton et al., 2007). As connectedness relates to engagement and negatively correlates with attrition, learning providers have been encouraged to ensure digital teaching resources promote student connectedness in order to alleviate challenges that are associated with online learning during COVID19 (Aguilera-Hermida, 2020). The purpose of this systematic review is to evaluate existing literature on the effectiveness of digital resources used in remote learning. It is anticipated that the findings of this systematic review can be adopted to facilitate 
the design of digital teaching methods that augment feelings of connectedness. To address the aim of exploring factors that promote connectedness under remote and blended learning, the following research question was devised: what are the characteristics of effective digital resource design when the aim of the resource is to build student connectedness? The following sub-questions were also considered to address the stated research aims: a) what factors contribute to connectedness in remote learning environments? b) what digital resources have been used to develop connectedness in remote learning environments? c) have digital resources been successful in developing connectedness in remote learning environments?

\section{Method}

\subsection{Objectives of the review}

This research aimed to explore factors that promote connectedness under digital learning approaches. To address this aim, a systematic review of literature was conducted using the following research question: what are the characteristics of effective digital resource design when the aim of the resource is to build student connectedness? The following sub-questions were also considered: a) what factors contribute to connectedness in remote learning environments? b) what digital resources have been used to develop connectedness in remote learning environments? c) have digital resources been successful in developing connectedness in remote learning environments?

Table 1 Stages of the systematic review

Research Stage

Stage 1. Data Searching

Search terms were applied to databases in psychology, education, and technology disciplines

Stage 2. Data Screening

Inclusion criteria were applied to the returns from data searching. Titles and abstracts were screened followed by full papers. References lists of selected papers were screened for further returns

Stage 3. Quality Appraisal

Two researchers used the Standard Quality Assessment Criteria for Evaluating Primary Research Papers from a Variety of Fields (Kmet et al., 2004) to evaluate the quality of the selected papers

Stage 4. Data Extraction and Analysis

The sample of papers were analysed using a thematic synthesis technique where repeat findings were coded. Two researchers conducted the coding procedure

Stage 5. Data Synthesis and Presentation

A discursive narrative approach was used to present the findings of the thematic review of papers 


\subsection{Design}

A systematic review was conducted between August and December 2020 in line with published guidance for undertaking reviews (Centre for Reviews and Dissemination, 2009). Table 1. presents a summary of the stages of the systematic review.

\subsection{Search Methods}

The inclusion criteria for this systematic review (Box 1) were developed to incorporate the disciplines of psychology, education, and technology. Literature was acquired using the following databases: APA Psych net (Info and Articles), Pro Quest Psychology, Science Direct, Scopus, Directory of Open Access Journals, High Wire Press, Taylor \& Francis, The Dart, EthOS and IEEE Explore. Databases were searched using combinations of the following terms: "campus connectedness", OR "'connectedness', OR "'psychological connectedness"' OR 'student connectedness' AND 'remote learning', $O R$ ''distance learning', $O R$ 'online learning', $O R$ ''e learning', OR 'digital learning', OR 'online education', OR ',education', $O R$ "'digital device,' OR 'digital resources"' OR 'technology'.

Box 1. Inclusion criteria.

International research papers written in English

Empirical research

Published and unpublished research evidence

Research papers that explore psychological connectedness as defined by Lee and Robbins (1995)

Research evidence that explores the link between digital teaching resources and connectedness outcomes amongst student populations

\subsection{Search Outcomes}

The initial paper identification search produced a total of 1,126 papers that met the inclusion criteria (after duplicates were removed). The PRISMA (Fig. 1.) study selection process was used to narrow the selection of papers based on the research aims and the inclusion criteria (Moher et al., 2009). A total of 17 articles remained after the study selection process was completed. Table 2 summaries the final sample of 17 papers included in the review.

\subsection{Quality appraisal}

Due to the heterogeneity of the papers selected for inclusion, the Standard Quality Assessment Criteria for Evaluating Primary Research Papers from a Variety of Fields (Kmet et al., 2004) was used to evaluate the quality of the sample of papers. Two authors independently rated each paper for inclusion. The authors 


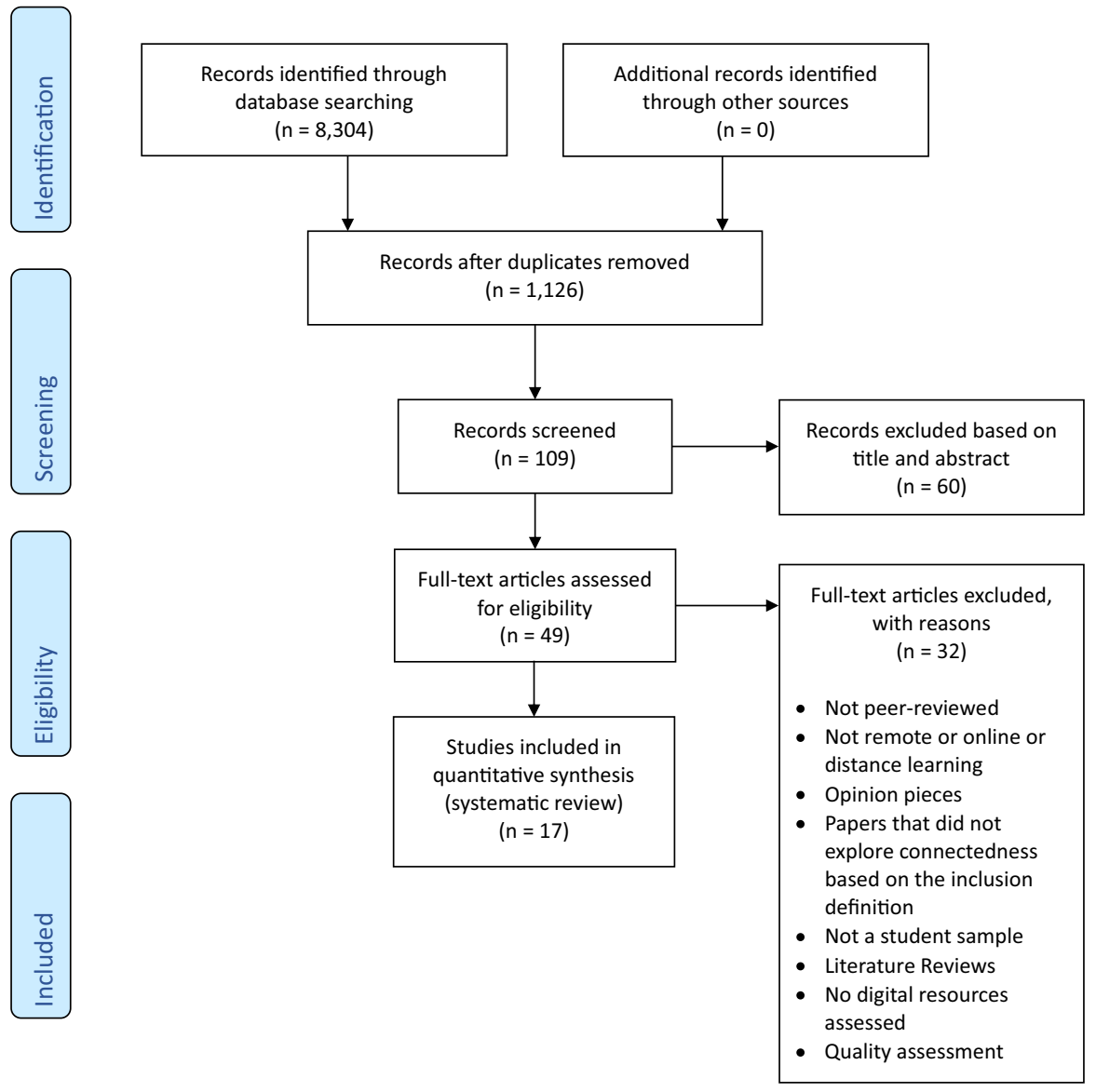

Fig. 1 PRISMA flow chart on paper identification, screening, eligibility assessments and inclusion

selected a minimum threshold for inclusion of 0.65 for the average summary score. This threshold reflected a balance between the relatively conservative figure of 0.75 and the relatively liberal value of 0.55 (Kmet et al., 2004). Only one paper (Slagter van Tryon \& Bishop, 2009) attained a score below the minimum threshold for inclusion (summary score: 0.50) and was excluded from the final sample. Table 3 provides a synopsis of the quality appraisal results for all papers.

\subsection{Data abstraction and synthesis}

Due to the heterogeneous nature of the articles included in the present review (i.e., correlation design, quantitative experimental studies, qualitative studies, literature reviews, and case studies) it was not possible to conduct a metaanalysis or further quantitative comparisons. Accordingly, the results were analysed using a thematic synthesis technique. Themes were developed using 


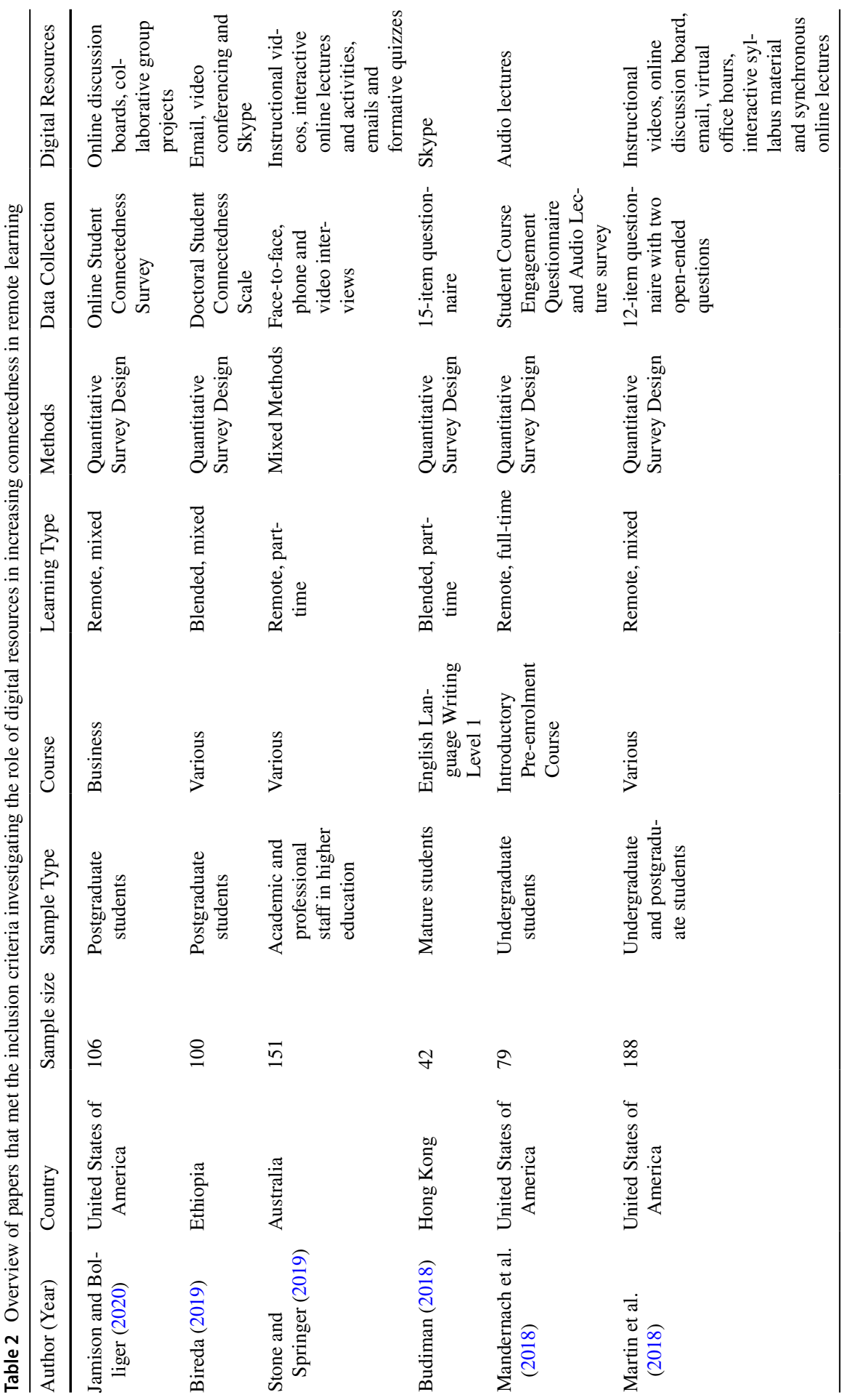




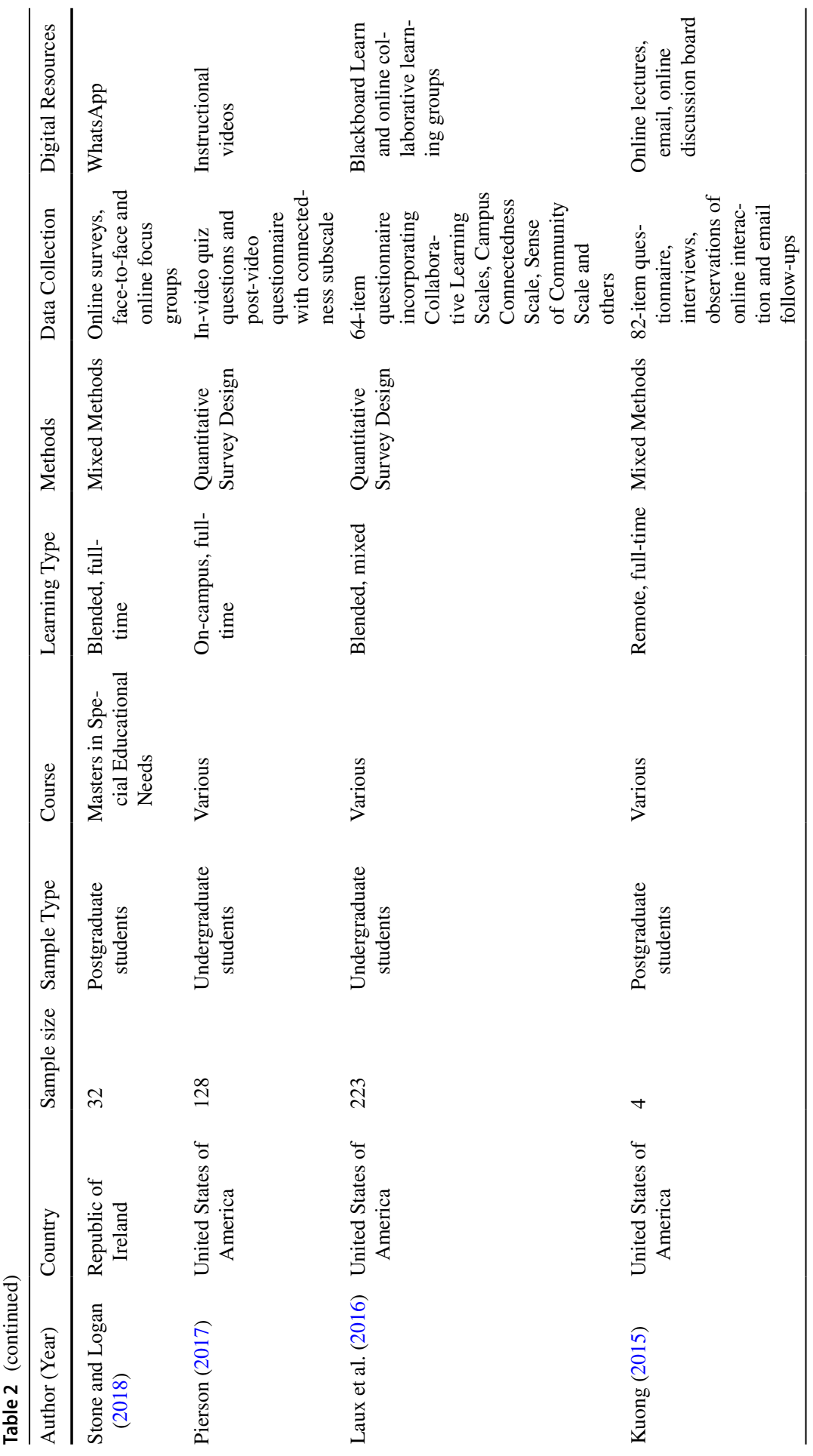




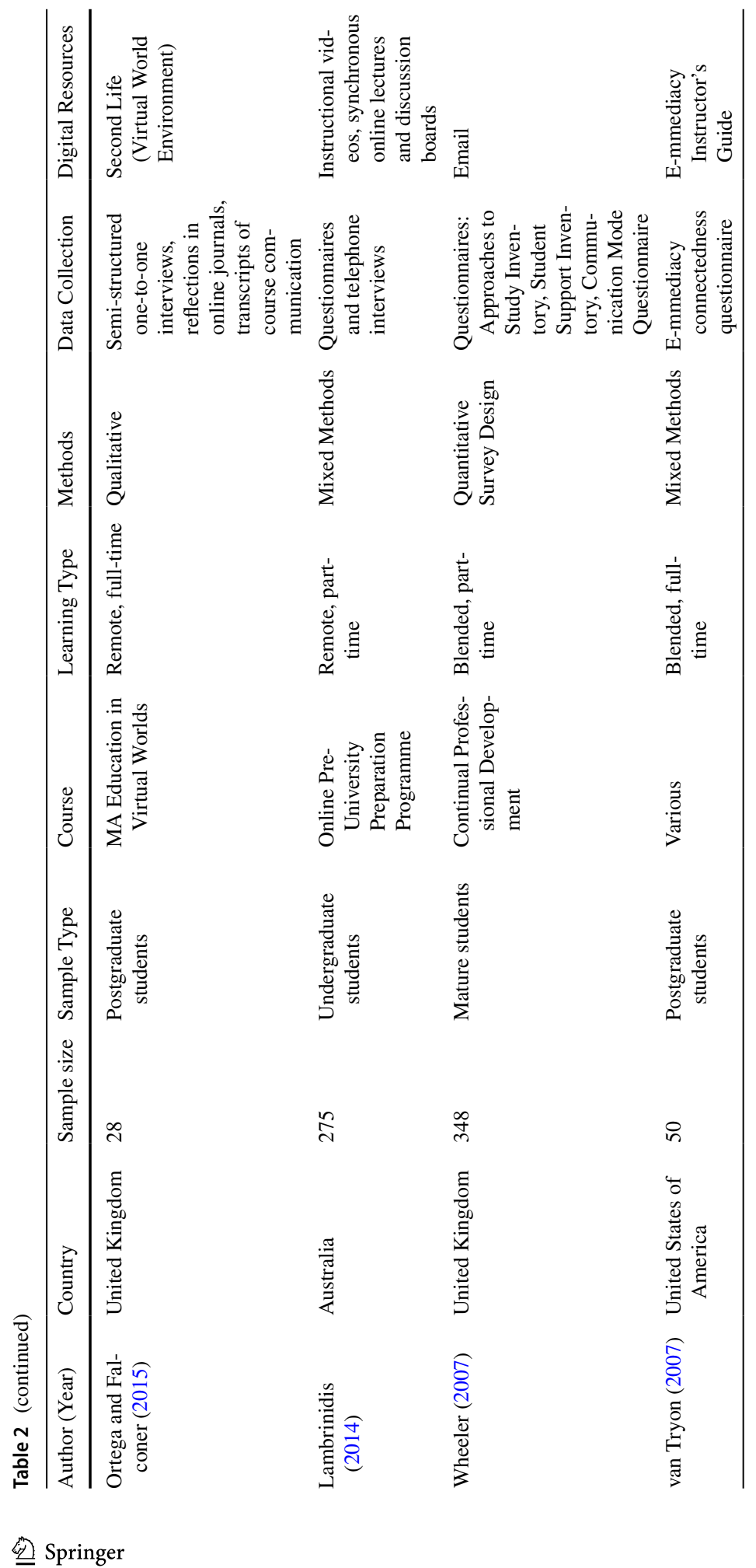




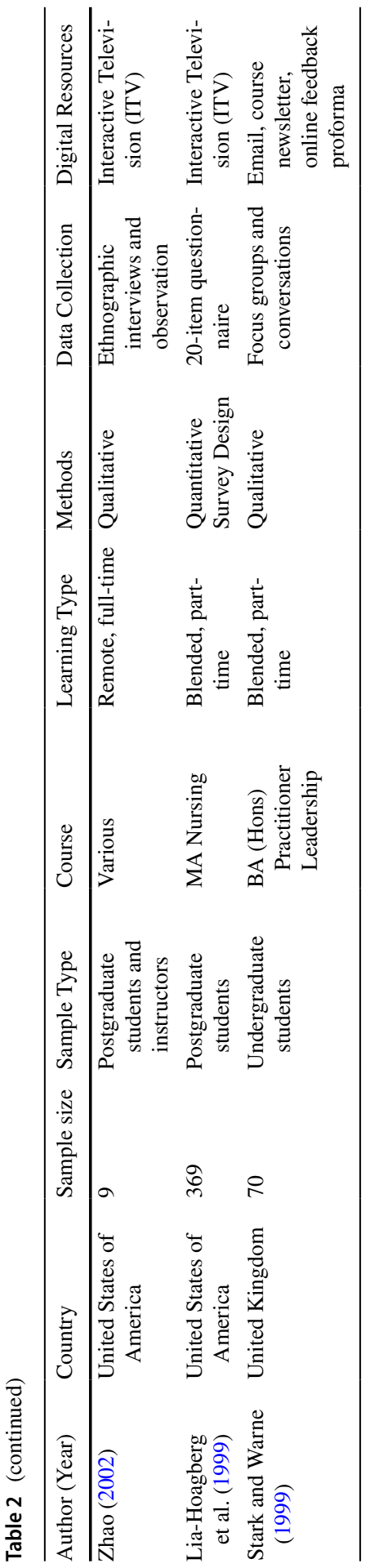


Table 3 Quality appraisal of the sample of 17 papers

\begin{tabular}{ll}
\hline Author/s (date) & $\begin{array}{l}\text { Average Sum- } \\
\text { mary Score }\end{array}$ \\
\hline Jamison and Bolliger (2020) & 0.93 \\
Bireda (2019) & 0.77 \\
Stone and Springer (2019) & 0.88 \\
Budiman (2013) & 0.70 \\
Mandernach et al. (2018) & 0.80 \\
Martin et al. (2018) & 0.91 \\
Stone and Logan (2018) & 0.85 \\
Pierson (2017) & 0.82 \\
Laux et al. (2016) & 0.80 \\
Kuong (2015) & 0.75 \\
Ortega and Falconer (2015) & 0.63 \\
Lambrinidis (2014) & 0.83 \\
Wheeler (2007) & 0.91 \\
van Tryon (2007) & 0.65 \\
Zhao (2002) & 0.68 \\
Lia-Hoagberg et al. (1999) & 0.89 \\
Stark and Warne (1999) & 0.85
\end{tabular}

Braun and Clarke's (2012) six step process for building themes. Using consensus coding, two researchers developed the themes and subthemes to present the research findings. The consensus approach offered validity of the findings and reduced the potential for researcher bias. Findings were presented using a discursive narrative approach. Both the analysis and data presentation technique offered a collective narrative thread from which themes could be derived (Thomas et al., 2012).

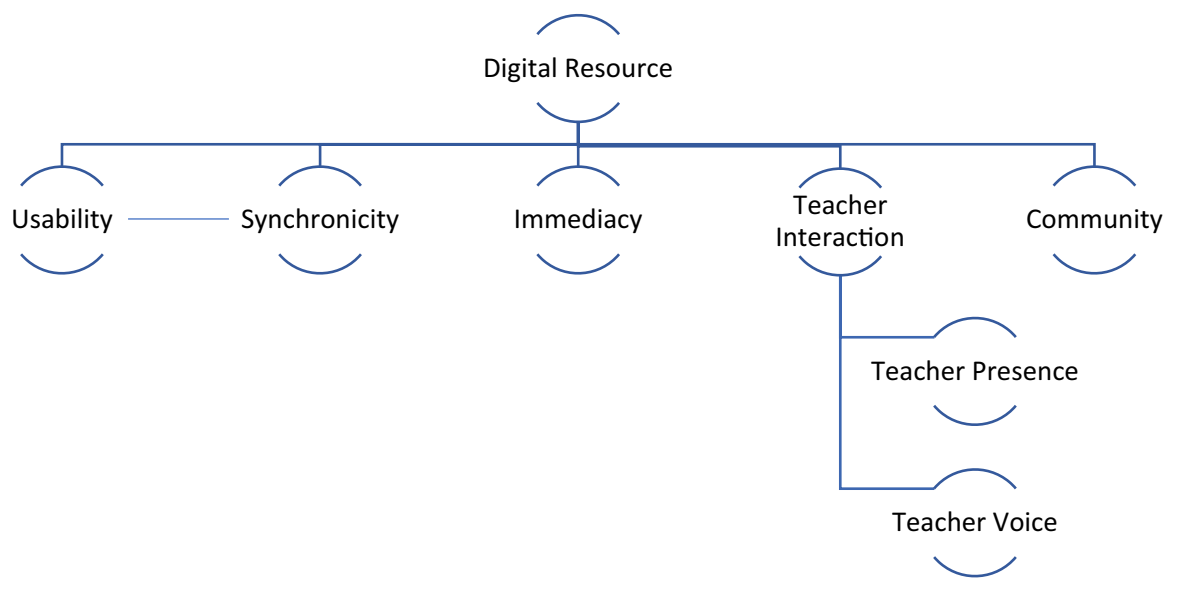

Fig. 2 Five characteristics of effective digital resources to enhance connectedness 


\section{Results}

Based on the final sample of papers $(\mathrm{N}=17)$, this systematic review was able to identify five key factors that are shown to encourage connectedness when using digital teaching methods. Usability, teacher presence, immediacy, synchronicity, and community were the five components identified as being essential to encourage student feelings of connectedness (Fig. 2). Figure two presents each theme and corresponding subthemes. The researchers suggest that digital resources should incorporate all aspects of the model presented in figure two. A narration of each theme is provided.

\subsection{Theme one: Usability}

Digital learning resources must have comprehensive IT support available to students to eliminate any accessibility issues and help foster connectedness (Slagter van Tryon \& Bishop, 2009). Laux et al. (2016) identified that familiarity and ease of use was more likely to increase connectedness in a remote learning environment than unfamiliar, difficult-to-use digital resources. Budiman (2018) similarly found that familiarity with a digital resource increased connectedness. Specifically, the ability to access the resource from both laptops and mobile phones was an important usability factor. Due to participants' familiarity with the technology, Ortega and Falconer (2015) found that embedding a virtual digital resource into the existing remote learning course was successful in increasing connectedness. Stone and Springer (2019) highlighted that accessibility issues with digital resources can act as a barrier to connectedness. They further concluded that an effective digital resource must be accessible to all students and easy to use. Kuong (2015) demonstrated the importance of functionality and highlighted that digital resources that utilise online discussion forums are user-friendly and allow additional convenience, flexibility, and time to reflect.

\subsection{Theme two: Teacher interaction}

Stone and Springer (2019) found that "teacher presence" increased connectedness. When teacher presence was a factor of the digital resource, students rated their perceptions of the remote learning environment as supportive, engaging, and inclusive. Stark and Warne (1999) showed that feelings of connectedness were impaired when student expectations of their relationship with the teacher were not met. Martin et al. (2018) identified that higher perceived professionalism of the teacher was associated with greater student connectedness. Although a positive correlation between student-to-teacher connectedness and student-student connectedness has been found (Bireda, 2019; Stone \& Logan, 2018), a positive student-teacher relationship has been shown to encourage feelings of involvement and engagement and therefore feelings of connectedness (Mandernach et al., 2018). Of central importance is the approachability of the teacher and immediate feedback was valued highly by students (Stark \& Warne, 1999). Students are more likely to feel connected to their course when their individual abilities are 
recognised by the teacher and when teachers engage in regular, meaningful communication (Stone \& Springer, 2019).

Two recurring sub-themes emerged throughout the literature that explain the importance of student-teacher relationships when building connectedness in remote learning scenarios.

\subsection{Subtheme: Teacher presence}

Stark and Warne (1999) highlighted the importance of teacher familiarity for developing connectedness under remote learning conditions. Similarly, Pierson (2017) found that seeing the teacher's face in an instructional video had a positive effect on students' self-reported feelings of connectedness, satisfaction, and engagement with the remote learning course. Tailored course material and personalised teacher interaction were strongly linked with student perception of teacher presence and the development of connectedness (Mandernach et al., 2018). Individual differences in student preferences for teacher presence in remote learning have been identified, but many prefer active interaction and participation in discussion from their teacher as opposed to passive teaching (Jamison \& Bolliger, 2020). Students reported feeling greater support with their course material and connection with their remote learning when there was a strong teacher presence (Wheeler, 2007). Stone and Springer (2019) highlight the importance of teacher presence in combination with regular and engaging course content in remote learning for student connectedness.

\subsection{Subtheme: Teacher voice}

Mandernach et al. (2018) found that personalised audio lectures featuring the teachers' voice increased student connectedness and engagement with the course. Stark and Warne (1999) refer to the aspect of 'human touch' for student connectedness in remote learning due to the limited face-to-face interaction in most courses. Lambrinidis (2014) identified that some students prefer hearing the teacher voice in instructional videos and synchronous online lectures as opposed to reading textbased messages in online discussion boards. Zhao (2002) found that students who reported audio difficulties with the digital resource and could not hear the teacher voice were less connected to their course and institution.

In the literature where teacher presence and voice were investigated simultaneously, Ortega and Falconer (2015) found that immersive virtual world technology helped create a sense of community and connectedness by recreating social interaction and communication. Here students were provided with personalised avatars within virtual environments both within course sessions and extracurricular activities. Lia-Hoagberg et al. (1999) demonstrated that the combination of teacher presence and voice in Interactive Television was linked with higher student connectedness with the teacher in a distance-learning site. Martin et al. (2018) found that 
video-based introductions led by the teacher at the start of the course were one of the highest-rated facilitation strategies to increase connectedness in remote learning.

\subsection{Theme Three: Immediacy}

Stark and Warne (1999) identified that immediate feedback to emails was one of the most important factors that increased students' connectedness to their teacher. Wheeler (2007) identified that of three communication strategies, students reported highest levels of connectedness from email as opposed to telephone or face-to-face due to the immediacy of detailed feedback. van Tryon (2007) examined a number of "e-mmediacy" strategies and found that digital resources that facilitated immediate interaction between students and their peers, as well as students and teachers, were most effective in developing connectedness. van Tryon (2007) advised that teachers would need to play a proactive role in facilitating communication with students if the digital resource did not accommodate immediate responses. Jamison and Bolliger (2020) identified that delayed responses from teachers was one of the key factors for students who reported lower levels of connectedness. Martin et al. (2018) found that students rated timely response to questions and instructors' timely feedback on assignments and projects highest in developing connectedness.

A lack of responsiveness and immediate feedback in remote learning is associated with course dissatisfaction and unhappiness in students as well as increased levels of attrition (Bireda, 2019; Stone \& Springer, 2019). When compared to responsive and available tutors, course satisfaction, happiness, and attrition increased (Stark $\&$ Warne, 1999). Students rate immediate responses as one of the most important factors when they experience a problem with their remote learning course with an increased level of motivation to continue to completion (Budiman, 2018). Immediate and tailored feedback via a digital resource is linked with increased student engagement and connectedness with their remote learning course, teacher and institution (Jamison \& Bolliger, 2020; Martin et al., 2018).

\subsection{Theme four: Synchronicity}

Lambrinidis (2014) found that online lectures that are conducted in combination with on-campus lectures increased connectedness in remote learners. This synchronicity allowed real-time interaction with peers and live feedback from teachers, both of which students reported as essential for connectedness. Zhao (2002) found that any digital resource needs to aim to recreate the physical, on-campus experience as much as possible. When online lectures run alongside physical lectures, students developed a greater sense of self-report connectedness. Kuong (2015) demonstrated a lack of synchronicity and immediate feedback is linked with lower student selfreported confidence, self-efficacy, and student-to-student connectedness in remote learning. Further, students demonstrated a strong preference for synchronous faceto-face interaction in discussions. Synchronous course sessions are associated with student self-reported confidence in using a digital resource in remote learning. Confidence and therefore usability, are also shown to build connectedness (Budiman, 
2018). Zhao (2002) demonstrated that difficulties with the administration and use of digital resources often resulted in asynchronous course sessions for students in remote learning which were linked with lower connectedness, disengagement, and a feeling of a loss of control.

\subsection{Theme five: Community}

Lambrinidis (2014) found that online lectures and discussion boards create a sense of community between distance learners and those studying on campus which is essential for connectedness. Zhao (2002) showed that digital resources develop connectedness in students over an extended period and is associated with an increasing sense of community. Jamison and Bolliger (2020) found that students reported a lack of sense of community in their remote learning courses as one of the key reasons for their lack of connectedness. Kuong (2015) also found that a lack of social connection and sense of community led to lower connectedness among remote learning students and suggested the need for a digital intervention. Laux et al. (2016) found that a digital intervention utilising collaborative learning groups helped develop a sense of community, which in turn increased connectedness and organisational commitment. Furthermore, developing a sense of community improved student turnover and reduced intention to dropout. A stronger sense of community is also associated with improved group collaboration and greater emotional support which is linked with increased student retention and satisfaction (Bireda, 2019).

\section{Discussion}

Collating research that explored the effectiveness of digital resources in developing connectedness, allowed researchers to create a model for innovative digital resource design. The model can be used to encourage student connectedness under distance, remote, and blended learning approaches. These findings reflect an international perspective and therefore can be deemed globally-relevant. It is suggested that to optimise connectedness amongst student populations, teacher practitioners develop digital resources in line with the current findings. The findings of this research highlighted that digital resources aid connectedness amongst students when usability, teacher presence, immediacy, synchronicity, and sense of community are incorporated. The researchers predict that connectedness will be optimised when the five themes are collectively incorporated into digital resource design.

The themes that emerged from the literature are telling of how connectedness is formed and maintained in remote learning. The literature explained how digital resources can enhance student connectedness in conjunction with these themes. Similarly, data also highlighted that connectedness can be implicated when digital teaching resources neglect to include the five factors. For example, immediacy is established in real life interaction via social cues and body language and online immediacy encourages feeling of connectedness. Online immediacy, such as instant feedback and timely responses on a chat group or email, replicates the 
social cues that are present in a real time interaction. Another example is that technology can also provide video or audio footage of tutors which emphasises teacher presence in real time scenarios. For example, Slagter van Tryon \& Bishop (2009) outlined that role differentiation, norm development, and status assessments encouraged group cohesion, the development of a sense of community, and therefore feelings of connectedness. However, when a sense of immediacy, lack of teacher presence, and community are impounded, connectedness is reduced.

Literature collated as part of this systematic review highlighted the importance of considering individual differences in digital resource design (Jamison \& Bolliger, 2020). Although the data presented general themes that are typically beneficial to developing connectedness amongst students, individual differences may act as an irregularity to increased feelings of connectedness under remote conditions. For example, individual differences between students in terms of motivation and commitment should be considered when reviewing experiences of connectedness in remote learning. A caveat of how connected students feel can be dependent on intrinsic motivation to engage, and therefore experience connectedness. Some students have little desire to be part of the learning community and do not require the feeling of connection to develop a positive student experience. In addition, some students may be unable to attend synchronous online lectures and group workshops due to other commitments such as childcare or other employment. Consequently, some student may prefer a more autonomous style of remote learning. As with teaching and learning strategies, differentiation and understanding the nature of the student cohort is an essential factor to consider when designing digital teaching resources. Future research should consider the implications of individual differences in feelings of connectedness under blended or remote learning conditions.

\subsection{Limitations of the research}

It is important for teacher practitioners to remain mindful of ambiguity within the literature in terms of how connectedness is framed. Connectedness is regarded by some as having a sense of community whereas others frame connectedness as a social or technological concern. The current review focused on psychological connectedness and adopted the operational definition presented by Lee and Robbins (1995). Therefore, the sample of papers included in the review reflected connectedness as framed by Lee and Robbins' (1995) definition (or alluded to, without being explicit). Although, the conclusions of this research are based on a combination of large numbers of quantifiable data and rich qualitative findings that are reflective of the student experience, the theoretical perspective is restricted to only psychological connectedness.

Further, due to the methods of data collection i.e., a range of qualitative, quantitative and mixed-methods approaches, the researchers were unable to conduct comparative analysis of the quantitative studies. A series of connectedness scales were used in the research papers that adopted quantitative survey design, comparisons between 
these scales were unfeasible. Therefore, the researchers adopted a thematic synthesis technique where the data was presented using a discursive narrative approach.

\section{Conclusions}

Education has been impacted by COVID-19 on a global scale. Reports of higher levels of anxiety and stress in students has impacted concentration and commitment to academic work (Borelli et al., 2020). Additionally, increased anxiety has impacted student confidence and preparedness (Choi et al., 2020), and ultimately caused delay in academic work (Cao et al., 2020). Academic work has also been affected by poor study environments, which has inevitably reinforced stress and anxiety amongst students. However, by incorporating usability, teacher presence, immediacy, synchronicity, and sense of community into digital resource design could offer the opportunity for students to develop a feeling of connectedness and overcome issues of isolation.

\section{Declarations}

Conflict of interest There are no conflicting or competing interests to publish this research. The researchers give consent to publish. The research was funded by a small internal university Ryley Award.

\section{References}

Aguilera-Hermida, A. P. (2020). College students' use and acceptance of emergency online learning due to Covid-19. International Journal of Educational Research Open. Advance online publication. https://doi.org/10.1016/j.ijedro.2020.100011.

Aristovnik, A., Keržič, D., Ravšelj, D., Tomaževič, N., \& Umek, L. (2020). Impacts of the COVID19 pandemic on life of higher education students: A global perspective. Sustainability, 12(20), 8438.

Alemany-Arrebola, I., Rojas-Ruiz, G., Granda-Vera, J., \& Mingorance-Estrada, Á. C. (2020). Influence of COVID-19 on the perception of academic self-efficacy, state anxiety, and trait anxiety in college students. Frontiers in psychology, 11. Advance online publication. https://doi.org/10. 3389/fpsyg.2020.570017.

Arslan, G. (2021). Loneliness, college belongingness, subjective vitality, and psychological adjustment during coronavirus pandemic: Development of the College Belongingness Questionnaire. Journal of Positive School Psychology, 5(1), 17-31.

Aucejo, E. M., French, J., Araya, M. P. U., \& Zafar, B. (2020). The impact of COVID-19 on student experiences and expectations: Evidence from a survey. Journal of public economics, 191. Advance online publication. https://doi.org/10.1016/j.jpubeco.2020.104271.

Bireda, A. D. (2019). Doctoral student connectedness in open distance learning: a case of students and supervisors. Africa Education Review, 16(5), 16-28.

Borelli, J., Lai, J., Yunusova, A., Rivera, A. P., Labbaf, S., Hu, S., .., Rahmani, A. (2020). Nine months in the life of a college student during 2020: A case study using multi-modal assessments to capture personalized contexts of well-being. Advance online publication. https://doi.org/10. 31234/osf.io/wb4ds.

Braun, V., \& Clarke, V. (2012). Thematic analysis. In H. Cooper, P. M. Camic, D. L. Long, A. T. Panter, D. Rindskopf, \& K. J. Sher (Eds.), APA handbooks in psychology. APA handbook of 
research methods in psychology, Vol. 2. Research designs: Quantitative, qualitative, neuropsychological, and biological (p. 57-71). American Psychological Association.

Brereton, P., Kitchenham, B. A., Budgen, D., Turner, M., \& Khalil, M. (2007). Lessons from applying the systematic literature review process within the software engineering domain. Journal of Systems and Software, 80(4), 571-583.

Bridgstock, R., Jackson, D., Lloyd, K., \& Tofa, M. (2019). Social connectedness and graduate employability: Exploring the professional networks of graduates from business and creative industries. In R. Bridgstock \& N. Tippett (Eds.), Higher Education and the Future of Graduate Employability. Northampton: Edward Elgar Publishing.

Budiman, R. (2013). Utilizing Skype for providing learning support for Indonesian distance learning students: A lesson learnt. Procedia - Social and Behavioral Sciences, 83, 5-10.

Budiman, R. (2018). Factors related to students' drop out of a distance language learning programme. Journal of Curriculum and Teaching, 7(2), 12-19.

Cao, W., Fang, Z., Hou, G., Han, M., Xu, X., Dong, J., \& Zheng, J. (2020). The psychological impact of the COVID-19 epidemic on college students in China. Psychiatry research, 287, 112934. Advance online publication. https://doi.org/10.1016/j.psychres.2020.112934.

Centre for Reviews and Dissemination (2009). Systematic Reviews: CRD's Guidance for Undertaking Systematic Reviews in Health Care. Retrieved January 07, 2021, from www.york.ac.uk/inst/crd/pdf/ Systematic_Reviews.pdf.

Choi, B., Jegatheeswaran, L., Minocha, A., Alhilani, M., Nakhoul, M., \& Mutengesa, E. (2020). The impact of the COVID-19 pandemic on final year medical students in the United Kingdom: a national survey. BMC Medical Education, 20(1), 1-11.

Czerkawski, B. C., \& Lyman, E. W. (2016). An instructional design framework for fostering student engagement in online learning environments. TechTrends, 60(6), 532-539.

Elmer, T., Mepham, K., \& Stadtfeld, C. (2020). Students under lockdown: Assessing change in students' social networks and mental health during the COVID-19 crisis. PLoS ONE, 15(7), e0236337.

Farid, S., Ahmad, R., Alam, M., Akbar, A., \& Chang, V. (2018). A sustainable quality assessment model for the information delivery in E-learning systems. Information Discovery and Delivery., 40(1), 125.

Jamison, T. E., \& Bolliger, D. U. (2020). Student perceptions of connectedness in online graduate business programs. Journal of Education for Business, 95(5), 275-287.

Kmet, L. M., Cook, L. S., \& Lee, R. C. (2004). Standard quality assessment criteria for evaluating primary research papers from a variety of fields. Alberta Heritage Foundation for Medical Research. https://doi.org/10.7939/R37M04F16.

Kuong, H. C. (2015). Enhancing online learning experience: From learners' perspective. Procedia-Social and Behavioral Sciences, 191, 1002-1005.

Kuwabara, K., Watanabe, T., Ohguro, T., Itoh, Y., \& Maeda, Y. (2002). Connectedness oriented communication: Fostering a sense of connectedness to augment social relationships. Paper presented at the Proceedings 2002 symposium on applications and the internet (saint 2002).

Lai, J. W., \& Bower, M. (2020). Evaluation of technology use in education: Findings from a critical analysis of systematic literature reviews. Journal of Computer Assisted Learning, 36(3), 241-259.

Lambrinidis, G. (2014). Supporting online, non-traditional students through the introduction of effective e-learning tools in a pre-university tertiary enabling programme. Journal of Higher Education Policy and Management, 36(3), 257-267.

Laux, D., Luse, A., \& Mennecke, B. E. (2016). Collaboration, connectedness, and community: An examination of the factors influencing student persistence in virtual communities. Computers in Human Behavior, 57, 452-464.

Lee, R. M., \& Robbins, S. B. (1995). Measuring belongingness: The social connectedness and the social assurance scales. Journal of Counselling Psychology, 42(2), 232-241.

Lia-Hoagberg, B., Vellenga, B., Miller, M., \& Li, T.-Y. (1999). A partnership model of distance education: Students' perceptions of connectedness and professionalization. Journal of Professional Nursing, 15(2), 116-122.

Liu, X., Burroughs, N. F., Tian, Q., Harvey, V. L., Housel, T. H., \& Wellingon, N. (2016). The impact of smartphone educational use on student connectedness and out-of-class involvement. Electronic Journal of Communication, 26(3-4).

Mandernach, B. J., Robertson, S. N., \& Steele, J. P. (2018). Beyond Content: The Value of InstructorStudent Connections in the Online Classroom. Journal of the Scholarship of Teaching and Learning, 18(4), 129-150. 
Martin, F., Wang, C., \& Sadaf, A. (2018). Student perception of helpfulness of facilitation strategies that enhance instructor presence, connectedness, engagement and learning in online courses. The Internet and Higher Education, 37, 52-65.

Moher, D., Liberati, A., Tetzlaff, J., Altman, D. G., \& The Prisma Group. (2009). Preferred reporting items for systematic reviews and meta-analyses: the PRISMA statement. PLoS Medicine, 6(7), e1000097.

Motala, S., \& Menon, K. (2020). In search of the 'new normal': Reflections on teaching and learning during Covid-19 in a South African university. Southern African Review of Education, 26(1), 80-99.

Ortega, M. C. G., \& Falconer, L. (2015). Learning spaces in virtual worlds: Bringing our distance students home. Journal of Applied Research in Higher Education, 7(1), 83-98.

Osman, M. E. (2020). Global impact of COVID-19 on education systems: the emergency remote teaching at Sultan Qaboos University. Journal of Education for Teaching, 46(4), 463-471.

Pierson, A. (2017). The effect of seeing an instructor's face within an instructional video on connectedness, attention, and satisfaction. (Ph. D), Northcentral University, San Diego. (10289276).

Sahu, P. (2020). Closure of universities due to Coronavirus Disease 2019 (COVID-19): impact on education and mental health of students and academic staff. Cureus, 12(4). https://doi.org/10.7759/cureus. 7541.

Slagter van Tryon, P. J., \& Bishop, M. (2009). Theoretical foundations for enhancing social connectedness in online learning environments. Distance Education, 30(3), 291-315.

Stark, S., \& Warne, T. (1999). 'Connecting' the distance: Relational issues for participants in a distance learning programme. Journal of Further and Higher Education, 23(3), 391-402.

Stone, C., \& Springer, M. (2019). Interactivity, connectedness and'teacher-presence': Engaging and retaining students online. Australian Journal of Adult Learning, 59(2), 146-169.

Stone, S., \& Logan, A. (2018). Exploring students' use of the social networking site WhatsApp to foster connectedness in the online learning experience. Irish Journal of Technology Enhanced Learning Ireland, 3(1), 42-55.

Thistlethwaite, J., Locke, R., Buckley, S., Chandratilake, M., Jensen, G., van Schalkwyk, S., \& WellerNewton, J. (2020). Global perspectives on Covid-19 from the editorial board. The Clinical Teacher, 17(3), 234.

Thomas, J., Harden, A., \& Newman, M. (2012). Synthesis: Combining Results Systematically and Appropriately. Sage Publications.

van Tryon, P. J. S. (2007). E-mmediacy strategies for online learning: An instructor's guide and instrument for the design and evaluation of social connectedness in web-based courses. (Doctor of Education in Educational Technology), Lehigh University, Pennsylvania. (3314496).

Wheeler, S. (2007). The influence of communication technologies and approaches to study on transactional distance in blended learning. Research in Learning Technology, 15(2), 103-117.

Wiederhold, B. K. (2020). Connecting through technology during the coronavirus disease 2019 pandemic: Avoiding “Zoom Fatigue." Cyberpsychology, Behaviour, and Social Networking, 23(7), 437-438.

Wilson, K. M. (2018). School Connectedness and Academic Success. (Master of Arts), Old Dominion University, Sociology and Criminal Justice Thesis and Dissertations. Retrieved January 07, 2021, from https://digitalcommons.odu.edu/sociology_criminaljustice_etds/21.

Wyn, J., Cuervo, H., Woodman, D., \& Stokes, H. (2005). Young people, wellbeing and communication technologies. Melbourne, VicHealth.

Zhao, L. (2002). Interactive television in distance education: Benefits and compromises. Paper presented at the IEEE 2002 International Symposium on Technology and Society (ISTAS'02). Social Implications of Information and Communication Technology. Proceedings (Cat. No. 02CH37293).

Publisher's note Springer Nature remains neutral with regard to jurisdictional claims in published maps and institutional affiliations. 